OPEN ACCESS

Edited by:

Peter Falkai,

LMU Munich University

Hospital, Germany

Reviewed by:

Antonio Federico,

University of Siena, Italy

Daniel Cezary Zielonka,

Poznan University of Medical

Sciences, Poland

*Correspondence:

Maria Judit Molnar

molnar.mariajudit@

med.semmelweis-univ.hu

Specialty section:

This article was submitted to

Psychopharmacology,

a section of the journal

Frontiers in Psychiatry

Received: 30 November 2021 Accepted: 22 December 2021

Published: 10 February 2022

Citation:

Molnar MJ, Molnar V, Fedor M, Csehi R, Acsai K, Borsos B and Grosz $Z$ (2022) Improving Mood and Cognitive Symptoms in Huntington's Disease With Cariprazine Treatment. Front. Psychiatry 12:825532. doi: 10.3389/fpsyt.2021.825532

\section{Improving Mood and Cognitive Symptoms in Huntington's Disease With Cariprazine Treatment}

\author{
Maria Judit Molnar ${ }^{1 *}$, Viktor Molnar ${ }^{1}$, Mariann Fedor ${ }^{1}$, Reka Csehi ${ }^{2}$, Karoly Acsai ${ }^{2}$, \\ Beata Borsos ${ }^{1}$ and Zoltan Grosz ${ }^{1}$
}

${ }^{1}$ Institute of Genomic Medicine and Rare Disorders, Semmelweis University Budapest, Budapest, Hungary, ${ }^{2}$ Global Medical Division, Richter Gedeon Plc., Budapest, Hungary

In Huntington's disease (HD), the main clinical symptoms include depression, apathy, cognitive deficits, motor deficiencies and involuntary movements. Cognitive, mood and behavioral changes may precede motor symptoms by up to 15 years. The treatment of these diverse symptoms is challenging. Tetrabenazine and deutetrabenazine are the only medications specifically approved for Huntington's chorea, but they do not affect the non-motor symptoms. For these, antidepressants, antipsychotics, and benzodiazepines have demonstrated benefit in some cases and can be used off-label. These drugs, due to sedative side effects, may negatively influence cognition. Sixteen patients having HD received a 12-week off-label cariprazine (CAR) treatment (1.5-3 mg/day). Cognitive performance and behavioral changes were measured by the Addenbrooke Cognitive Examination (ACE) test, the Cognitive and Behavioral part of the Unified Huntington's Disease Rating Scale (UHDRS), and the Beck Depression Inventory (BDI). Mixed model for repeated measures was fitted to the data, with terms of visit, baseline $(B L)$ and their interaction. Cariprazine treatment resulted in the following changes from $B L$ to week 12 , respectively: the mean score of $\mathrm{BDI}$ decreased from $17.7 \pm 10.7$ to $10.0 \pm 10.7(p<$ 0.0097), while the Behavioral Assessment score of the UHDRS decreased from 54.9 \pm 11.3 to $32.5 \pm 15.4(p<0.0001)$; ACE score increased from $75.1 \pm 11.0$ to 89.0 $\pm 9.3(p<0.0001)$; Cognitive Verbal Fluency score from $6.2 \pm 2.5$ to $7.7 \pm 2.7(p<$ $0.0103)$; Symbol Digit Test from $9.2 \pm 6.9$ to $12.3 \pm 8.9$ ( $p<0.0009$ ). Mild akathisia was the most frequent side effect, presenting in 2 out of 16 patients (12.5\%). We conclude that CAR had a positive effect on depressive mood, apathy and cognitive functions in patients with early stage of HD. Based on the neurobiological basis of these symptoms, CAR can improve the dopamine imbalance of the prefrontal cortex. This draws attention to the transdiagnostic approach which supports the further understanding of the similar symptomatology of different neuropsychiatric disorders and helps to identify new indications of pharmaceutical compounds.

Keywords: Huntington's disease, cariprazine, apathy, cognitive decline, behavioral alteration, mood 


\section{INTRODUCTION}

\section{Huntington's Disease}

Huntington's disease (HD) is an autosomal dominantly inherited polyglutamate repeat expansion disease causing neurodegeneration in the brain. In the huntingtin (HTT) gene the expansion of an unstable polymorphic trinucleotide repeat $(\mathrm{CAG})$ region located within the open reading frame at the $5^{\prime}$ end of the first exon is responsible for the disease. In HD individuals the range of the expanded CAG repeats is between 36 and 250 (1). There is an inverse correlation between the number of repeats with onset, severity and progression of the disease. However, at least 6 genes are known to have a modulating effect on disease manifestation (2). The pathomechanism is related to the CAG repeat expansion in the HTT gene, which results in complex pathophysiological changes (3) affecting mitochondrial function, mitophagy and immune system as well (4). The clinical picture is dominated by motor symptoms (chorea, at end stage akinetic-rigorous hypokinesis), and non-motor features, such as cognitive dysfunction (including executive dysfunction, planning difficulties, cognitive decline), depression, apathy, irritability and behavioral disinhibition (e.g., making inappropriate comments, impulsivity, hypersexuality). Non-motor symptoms can appear before the motor symptoms, and are very strong predictors of loss of independence and quality of life.

\section{Role of Dopamine in Huntington's Disease}

Dopamine (DA) as a major neurotransmitter has essential roles regulating motor function, motivation, reward/pleasure, spatial memory function, lactation, and nausea (5). Five subtypes of dopamine receptors are known and classified into two receptor classes, class D1 and class D2. D1 and D5 receptor subtypes belong to class D1, while D2, D3, and D4 subtypes belong to class D2. The two most important dopamine receptors in the pathophysiology of neuropsychiatric disorders are the D2 and D3. The highest expression of D3 receptors is localized in the islands of Calleja, but is expressed throughout the limbic circuits, including the prefrontal cortex (PFC) (6), while the highest expression of D2 is linked to the striatum. Three major dopaminergic pathways are thought to be involved in HD: the mesolimbic pathway, projecting from the ventral tegmental area to the ventral striatum in the forebrain; the mesocortical pathway projecting from the ventral tegmental area to the prefrontal cortex; and the nigrostriatal pathway connecting the substantia nigra and the caudate and putamen. These loops maintain physiological regulation on behavior and voluntary movement.

In $\mathrm{HD}$, the dopamine balance in the striatum and the frontal lobe is altered, leading to changes in motion, cognitive and behavioral performance. In early stages of the disease, the amount of DA is increased while the expression of DA receptors is decreased. In later stages, similar to Parkinson's disease, the amount of DA declines $(7,8)$. First over- then under-production of DA mirrors the biphasic changes in motor symptoms characteristic of HD patients throughout the disease course $(9,10)$. Optimal function of the non-motor symptoms depends on the constant level of DA. Both low and high levels of DA lead to behavioral, mood, and cognitive malfunction (11).
Increasing evidence suggests the crucial role of the dopaminergic system in the development of HD symptoms, therefore DArelease modulating compounds might be a promising therapeutic option. DA stabilizing compounds, such as dopamine partial agonists, can increase or decrease DA receptor activity depending on the dopamine levels at the synapse.

\section{Treatment Approaches of HD}

There is a definite unmet need for causative therapies in HD. Several approaches have been designed to reduce mutant huntingtin (mHTT) concentrations in the CNS such as (1) non-allele-selective antisense oligonucleotides (ASOs); (2) gene editing strategies, including zinc finger nucleases, transcription activator-like effector nucleases, clustered regularly interspaced short palindromic repeats (CRISPR-Cas 9) techniques; (3) gene therapy, and (4) stem cells reprogramming with single-stranded RNAs, mismatch-containing RNAs, antisense oligonucleotide, and small hairpin RNA (12). However, ultimate treatment solutions are not yet available, therefore the treatment of HD still heavily relies on symptomatic treatment.

Tetrabenazine (TBZ) and deutetrabenazine (deuTBZ) are approved for the treatment of motor symptoms in $\mathrm{HD}$, such as chorea. TBZ is an inhibitor of the vesicular monoamine transporter 2 and its most prevalent dose-limiting side effects include somnolence, insomnia, depressed mood, akathisia, and parkinsonism (13). The deuterated form of hydrogen molecules in deuTBZ has a longer half-life requiring less frequent daily dosing, and likely having a better tolerability profile than TBZ. Thus, far, no study has compared TBZ and deuTBZ directly. A network meta-analysis of FIRST-HD and TETRA-HD studies showed that deuTBZ and TBZ had similar anti-chorea effect and safety profile, while patients receiving TBZ were more prone to experiencing depressive symptoms and somnolence (14). An indirect treatment comparison found a greater association between TBZ-use and neuropsychiatric adverse events, like akathisia and parkinsonism, compared to deuTBZ-use (15).

Clinical trial data is lacking on the management of non-motor symptoms. The clinical trial with buspirone to treat apathy had a negative result (16). Currently, dextromethorphan/quinidine and SRX46, a vasopressin 1A receptor antagonist, are being assessed for irritability (12), while psychiatric symptoms are treated based on expert consensus ${ }^{1}$. Selective serotonin reuptake inhibitors (SSRI) and serotonin-norepinephrine reuptake inhibitors (SNRI) are recommended for both depression and anxiety, while irritability is managed by sedative antidepressants, antipsychotics, or mood stabilizers. However, the treatment of apathy and cognitive symptoms in HD remains challenging. To improve cognition, two small clinical trials were not able to confirm the efficacy of cholinesterase inhibitors (17). A Phase 2 trial with SAGE-718 (NMDA receptor modulation) will start in the near future ${ }^{2}$ and a Phase1b open label trial is ongoing with nilotinib, to increase the dopamine level (NCT03764215).

\footnotetext{
${ }^{1}$ https://www.gedeonrichter.com/en/news/211029

${ }^{2}$ https://investor.sagerx.com/news-releases/news-releasedetails/sage-

therapeutics-receives-fast-track-designation-sage- 718
} 


\section{Cariprazine}

Cariprazine (CAR) is a third-generation antipsychotic approved for the treatment of schizophrenia as well as for the depressive and manic and mixed episodes associated with bipolar I disorder in adult patients ${ }^{3}$. Furthermore, two studies had positive results for the adjunctive treatment of major depression disorder $(\mathrm{MDD})^{1}$. Cariprazine is a dopamine D3 receptor preferring partial agonist at the $\mathrm{D} 2 / \mathrm{D} 3$ receptors as well as at the serotonin 5-HT1A receptors, and acts as an antagonist at the 5-HT2B receptors (18). In fact, cariprazine's affinity to the D3 receptors is stronger than that of any other antipsychotics or even dopamine itself (19). Due to other antipsychotics' low affinity and dopamine's high affinity for the D3 receptors, antipsychotics (except for cariprazine) cannot occupy the D3 receptors in the presence of dopamine in the living brain (20). Therefore, only cariprazine is known to have the potential to dock to these receptors and exhibit the effects usually associated with D3 receptor blockade, which include improvements in negative, cognitive and depressive symptoms as well as in motivation and reward (21).

\section{Study Aims}

This study aimed to explore the effects of 12-week cariprazine treatment on the mood and cognitive symptoms associated with Huntington's disease.

\section{MATERIALS AND METHODS}

\section{Patients}

All patients had an abnormal expansion in the HTT gene (CAG $>36$ ) and were clinically diagnosed according to the diagnostic confidence level of the Unified Huntington's Disease Rating Scale (UHDRS). The diagnostic confidence level ranges from 0 (normal) to 4 (unequivocal extrapyramidal signs of $\mathrm{HD}, \geq 99 \%$ confidence of the examiner).

The stage of the disease was identified by the Total Functional Capacity (TFC) of the UHDRS. Based on the TFC score, patients were classified into five stages that indicate levels of disease severity based on functional decline. Patients in Stage I had TFC scores of 11-13 (least severe); Stage II for scores 7-10; Stage III for scores 3-6; Stage IV for scores 1-2; and Stage V for a score of 0 (most severe).

All participants received the permission for off-label use of cariprazine issued by the Hungarian National Institute of Pharmacy and Nutrition. The study was conducted in accordance with the Declaration of Helsinki and all patients provided written informed consent.

\section{Study Design}

This is a retrospective study aiming to evaluate the effect and safety of cariprazine in the treatment of non-motor (mood, behavioral, and cognitive) symptoms of Huntington's disease (Table 1). Efficacy and safety parameters were evaluated on week 8 and 12.

Cariprazine was indicated if the patient had either mood symptoms (loss of motivation, apathy, anhedonia,

${ }^{3}$ https://www.accessdata.fda.gov/drugsatfda_docs/label/2019/204370s006lbl.pdf depression) or cognitive alterations (executive dysfunction, planning difficulties, cognitive decline). The initial dose of CAR was $1.5 \mathrm{mg} /$ day in the morning, which was increased to $3 \mathrm{mg} /$ day if needed. Co-medications like tetrabenazine, benzodiazepines, antidepressants or antipsychotics were allowed if needed (Table 1). During the 12 week observational period of the study as new medication only procyclidine was introduced if akathisia appeared.

\section{Efficacy Evaluations}

The study duration was 12 weeks. All efficacy parameters were evaluated at baseline, on week 8 and 12. Changes from baseline in mood and behavior were measured by the Beck Depression Inventory (BDI) and the Behavioral Assessment in the UHDRS scale. The BDI is a 21 -item, self-report rating inventory that measures characteristic attitudes and symptoms of depression (22). The UHDRS scale was developed by the Huntington Study Group in 1996, updated in 1999 and its Cognitive and Behavioral Sections were clarified in 2005 (23).

Changes from baseline in cognitive performance was evaluated using the Addenbrooke Cognitive Examination (ACE) test and the Cognitive part of the UHDRS (computerized Stroop Test, Symbol Digit test, and Cognitive Verbal Fluency). The ACE consists of 19 activities in five cognitive domains: attention, memory, fluency, language and visuospatial processing $(24,25)$. The computerized Stroop Interference Test of the Vienna Test System (SCHUHFRIED GMBH Austria) was only performed at baseline, as it was highly challenging for the patients due to motor symptoms or cognitive impairment.

\section{Safety Evaluations}

Safety assessments performed at baseline, 8 and week 12 included: body weight, vital signs, neurological examination, ECG, and routine laboratory testing along with assessments of motor functioning and adverse events.

\section{Statistical Analysis}

Efficacy parameters were analyzed by mixed model for repeated measures (MMRM) separately for each parameter, with the terms of visit, baseline parameter value and their interaction, assuming unstructured covariance structure and using Kenward-Roger's approximation of the degrees of freedom. Least square (LS) means of the parameters (changes) by visits were estimated and compared between visits. Results are expressed as arithmetic means $(+/$ - standard error) and statistics are related to the LS means $(+/-$ standard error) of change from baseline (BL). If not otherwise stated, number of patients were 15 . Because of the exploratory nature of the study, and since the changes might be correlated between the efficacy parameters, no adjustment for the possible increase of the type I error rate were applied, and differences were considered significant when $p<0.05$.

\section{RESULTS}

\section{Patients}

Our cohort consisted of four males and twelve female patients with a mean age of 48.13 years ( \pm 26 yrs., SD 10.60) and mean disease duration of 3.78 years $( \pm 6.22$, SD 2.88). The average 
TABLE 1 | Demographic and clinical measures of participants.

\begin{tabular}{|c|c|c|c|c|c|c|c|c|c|}
\hline Patient Id & Sex & Age & AOO & Repeats & TFC & Stage & Dose of CAR & Co-medication & Side effect \\
\hline P1 & M & 44 & 40 & $23 / 50$ & 10 & 1 & $1.5 \mathrm{mg}$ & Tetrabenazine $2 \times 25 \mathrm{mg}$ & None \\
\hline P2 & $\mathrm{F}$ & 50 & 49 & $21 / 50$ & 10 & 1 & $1.5 \mathrm{mg}$ & Tetrabenazine $3 \times 25 \mathrm{mg}$ & None \\
\hline P3 & $\mathrm{F}$ & 53 & 48 & $22 / 41$ & 10 & 1 & $1.5 \mathrm{mg}$ & $\begin{array}{l}\text { Tetrabenazine } 3 \times 7.5 \mathrm{mg} \\
\text { Paroxetin } 1 \times 20 \mathrm{mg}\end{array}$ & Akathisia \\
\hline P4 & $\mathrm{F}$ & 56 & 54 & $23 / 42$ & 7 & $\|$ & $1.5 \mathrm{mg}$ & Alprazolam $3 \times 0.5 \mathrm{mg}$ & None \\
\hline P5 & $\mathrm{F}$ & 50 & 45 & $21 / 48$ & 12 & 1 & $3 \mathrm{mg}$ & Glimepirid 1 × 4 mg & Akathisia \\
\hline P6 & $\mathrm{F}$ & 38 & 31 & $19 / 47$ & 10 & 1 & $1.5 \mathrm{mg}$ & $\begin{array}{l}\text { Tetrabenazine } 4 \times 25 \mathrm{mg} \\
\text { Tiapridal } 1 \times 100 \mathrm{mg}\end{array}$ & None \\
\hline P7 & $\mathrm{F}$ & 42 & 41 & $18 / 44$ & 15 & $\mathrm{P}$ & $4.5 \mathrm{mg}$ & None & None \\
\hline P8 & $\mathrm{F}$ & 55 & 40 & $17 / 48$ & 5 & $\|$ & $1.5 \mathrm{mg}$ & $\begin{array}{l}\text { Tetrabenazine } 2 \times 12.5 \mathrm{mg} \\
\text { Clonazepam } 3 \times 0.5 \mathrm{mg} \\
\text { Chlorprotixen } 3 \times 12.5 \mathrm{mg}\end{array}$ & None \\
\hline P9 & $\mathrm{M}$ & 76 & 46 & $20 / 41$ & 6 & $\|$ & $1.5 \mathrm{mg}$ & $\begin{array}{l}\text { Tetrabenazine } 3 \times 25 \mathrm{mg} \\
\text { Alprazolam } 1 \times 0.25 \mathrm{mg}\end{array}$ & None \\
\hline P10 & $\mathrm{F}$ & 45 & 41 & $23 / 48$ & 6 & $\|$ & $1.5 \mathrm{mg}$ & $\begin{array}{l}\text { Tiapridal } 3 \times 100 \mathrm{mg} \\
\text { Escitalopram } 1 \times 5 \mathrm{mg}\end{array}$ & None \\
\hline P11 & M & 57 & 34 & $26 / 46$ & 1 & III & $1.5 \mathrm{mg}$ & $\begin{array}{l}\text { Tetrabenazine } 4 \text { × } 25 \mathrm{mg} \\
\text { Sertraline } 1 \times 50 \mathrm{mg} \\
\text { Clopazipne } 1 \times 25 \mathrm{mg}\end{array}$ & None \\
\hline P12 & $\mathrm{F}$ & 44 & 40 & $15 / 48$ & 10 & 1 & $1.5 \mathrm{mg}$ & $\begin{array}{l}\text { Tetrabenazine } 3 \times 12.5 \mathrm{mg} \\
\text { Procyclidin } 2 \times 5 \mathrm{mg}\end{array}$ & Akathisia. Weight loss \\
\hline P13 & $\mathrm{F}$ & 68 & 39 & $23 / 44$ & 8 & $\|$ & $1.5 \mathrm{mg}$ & $\begin{array}{l}\text { Tetrabenazine } 3 \times 7.5 \mathrm{mg} \\
\text { Paroxetin } 1 \times 20 \mathrm{mg}\end{array}$ & None \\
\hline P14 & $\mathrm{F}$ & 45 & 40 & $16 / 40$ & 5 & $\|$ & $1.5 \mathrm{mg}$ & $\begin{array}{l}\text { Tetrabenazine } 3 \times 50 \mathrm{mg} \\
\text { Sertraline } 1 \times 50 \mathrm{mg}\end{array}$ & None \\
\hline P15 & M & 44 & 42 & $21 / 48$ & 12 & 1 & $1.5 \mathrm{mg}$ & Tiapridal $3 \times 100 \mathrm{mg}$ & None \\
\hline P16 & $\mathrm{F}$ & 37 & 36 & $20 / 48$ & 12 & 1 & $1.5 \mathrm{mg}$ & None & None \\
\hline
\end{tabular}

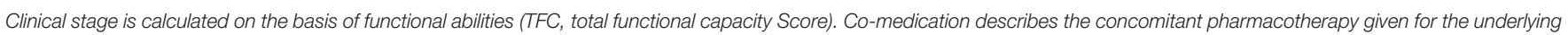
condition. Side-effect column contains observations about adverse-events recorded to be attributed to administration of cariprazine. AOO, age of onset; CAR, cariprazine.

size of the CAG repeat expansion on the pathological allele was 46 ( \pm 5, SD 3.28). One patient dropped out due to multiple events of non-compliance; hence, the presented efficacy analyses included data from $15 \mathrm{HD}$ patients, while safety data included all 16 patients. One patient was in pre-symptomatic stage having 15 points in the TFC, eight were in Stage I, six in Stage II, and one in Stage IV (Table 1).

\section{Efficacy Outcomes Mood and Behavioral Symptoms}

The severity of mood and apathy were evaluated by the Beck Depression Inventory and Behavioral Assessment from the UHDRS. The mean score of the BDI decreased from $17.7+10.7$ $(\mathrm{BL})$ to $10.0+10.7$ (LS mean of change $-7.7+/-2.6 p<0.0097)$ at week 12 (Figure 1A).

Baseline scores of on the Behavioral Assessment in the UHDRS showed that irritability, anxiety, depression, low selfestimation, disruptive behavior and apathy were the most severe symptoms (Figure 2). The overall Behavioral Assessment score of the UHDRS decreased from $54.9+11.3$ to $32.5+15.4$, (LS mean change $-22.53 .4 p<0.0001$ ) after 12 weeks (Figure 3).

\section{Cognitive Symptoms}

Neuropsychological investigation detected the following changes regarding the cognitive functions: mean Addenbrooke Cognitive
Examination total score increased from $75.1+11.0$ (baseline) to $86.7+9.3$ (week 12) (LS mean change $11.5+/-1.4 p<$ 0.0001 , Figure 1B). The Cognitive Verbal fluency score of the Cognitive part of the UHDRS was $6.2+2.5$ at the baseline, increased to $7.7+2.7$ by week 12 (LS mean change $1.5+/-0.5$, $p=0.0103)$. The mean baseline score of $9.2+6.9$ on the Symbol Digit test increased to $12.3+8.9$ by week 12 (LS mean change $3.1+/-0.7, p=0.0009$, Table 2). The data of the baseline Stroop Interference tests are shown in the Supplementary Table.

\section{Safety Outcomes}

The routine laboratory results (hematology and clinical chemistry) were within the normal range during the observation: serum glucose levels were slightly elevated in 3 patients at baseline (ranged between 6.3 and 7.1 $\mathrm{mmol} / \mathrm{l})$, however remained stable during the observation. Other laboratory parameters were within normal ranges. No significant changes were observed in vital signs, neurological examination, and ECG. Only a few patients reported experiencing side effects. Mild akathisia was the most frequent side effect, presenting in 2 of 16 patients $(12.5 \%)$. No CAR related safety concerns arouse in motor functions. 


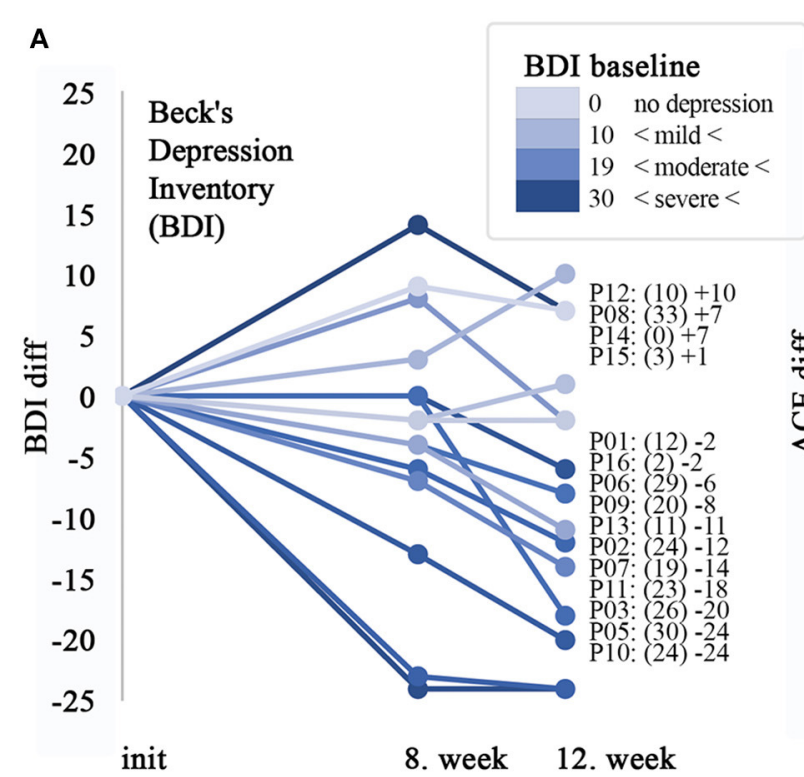

\section{B}

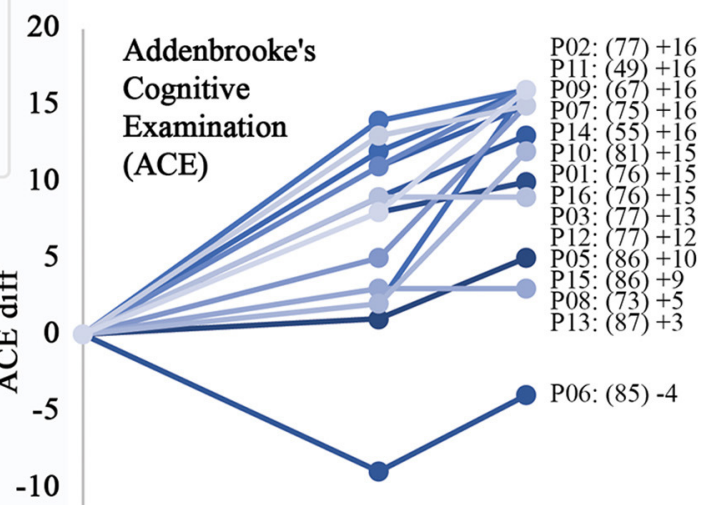

$-15$

$-20$
init
2. week

8. week

FIGURE 1 | Significant improvement in cognitive performance, which can only partly be explained by the effect on depression. Alteration of the cognitive performance and depression status of participants with $\mathrm{HD}$ after starting administration of cariprazine. (A) Line plot shows the difference in individual points scored by Beck's Depression Inventory (0-63) compared to the baseline and 8 and 12th weeks, respectively. Next to the diagram, all of the participating patients are listed in the order of the largest difference in observed change over the observation period. The baseline points in brackets, followed by change at the 12th week is shown. (B) Line plot for Addenbrook's Cognitive Examination (ACE) questionnaire (0-100). On both diagrams, the color intensity of the lines is proportional with the severity on the depression scale in a similar way.

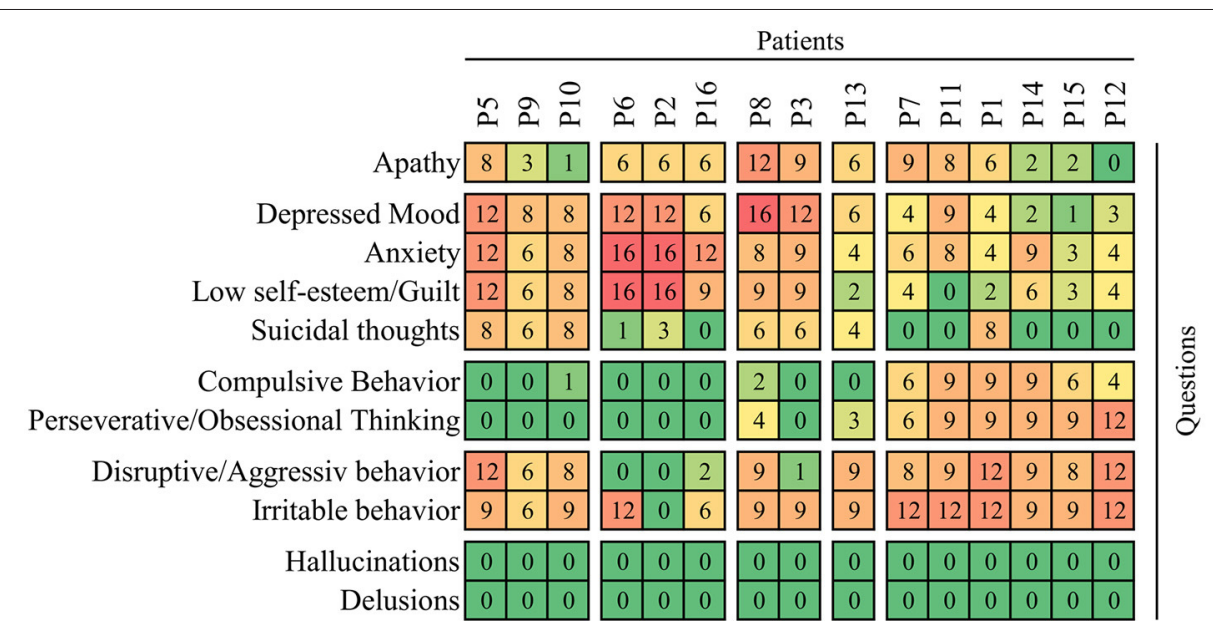

FIGURE 2 | Individual profiles of behavioral impairment at baseline of observation before administration of cariprazine. The frequency x severity scores are shown on the heatmap with the maximum 16 points calculated as product of 4 (which means very frequently, most all the time on a $0-4$ scale) and 4 (severe, causing a restriction of activities). The rows (questions/items) and columns (patients) are clustered on the basis of average correlation and separated in blocks according to first-order branches of dendrograms.

\section{DISCUSSION}

To our knowledge, this is the first paper providing data on the efficacy of CAR in Huntington's disease. Next to studies proving cariprazine's efficacy in schizophrenia, mania and depression associated with bipolar I disorder recent large-scale studies showed efficacy in adjunctive MDD treatment as well ${ }^{1}(26,27)$.
Moreover, CAR is the only antipsychotic with proven superiority over another antipsychotic in the treatment of predominant negative symptoms, including anhedonia, avolition-apathy, and alogia (28). Furthermore, there are post-hoc analyses demonstrating improvement of cognitive dysfunction in different psychiatric disorders after CAR treatment (29-32). Positive observations have been reported further in the following 


\section{UHDRS behavior assessment}

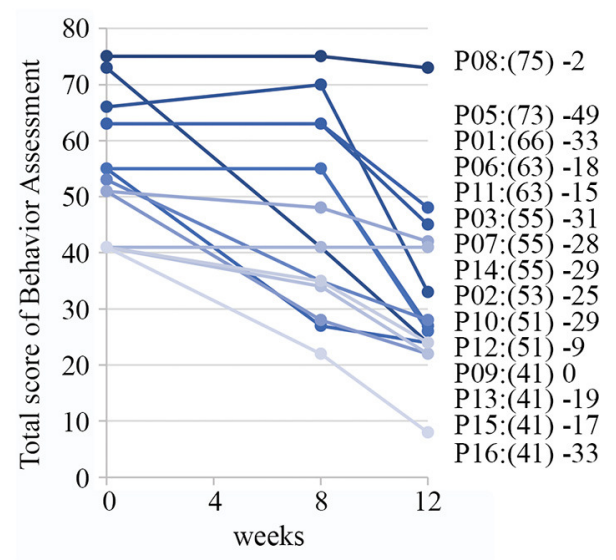

FIGURE 3 | Improvement on behavior assessment measures of UHDRS. Individual patient profiles are shown with captions including baseline sum of frequency $x$ severity scores in brackets and difference between baseline and assessed scores at the week 12.

indications: mitochondrial encephalomyopathy and lactic acidosis (MELAS syndrome) due to the mutation m.A3243G where the predominantly negative symptoms and cognitive dysfunction improved (33); substance use disorder (e.g., cocaine, alcohol, methamphetamine) (34, 35); obsessive-compulsive disorder as add-on therapy (36) and borderline personality disorder (37). Our study provides data for cariprazine's efficacy in non-motor symptoms of HD especially in loss of motivation, apathy, anhedonia, depression and cognitive symptoms.

In $\mathrm{HD}$, apathy is one of the most common psychiatric symptoms, frequently occurring several years before the onset of motor symptoms. Studies suggest that between 11 and $64 \%$ of pre-symptomatic, and $47-76 \%$ of symptomatic HD patients have apathy (38-40). Another equally prevalent symptom in HD is depression. McAllister and colleagues (41) analyzed the prevalence, timing, and functional impact of psychiatric, cognitive, and motor abnormalities in HD in more than 6,000 individuals from the European Huntington's Disease Network ${ }^{4}$. They found that the most prevalent symptom after motor symptoms was depression, occurring in $64.5 \%$ of individuals with HD. Differentiation between depression and apathy would be important since their pharmaceutical and behavioral therapies may differ. However, the clinical differentiation is challenging since the definition of these entities is overlapping and not constant across diseases $(42,43)$. Apathy covers different aspects of a loss in motivation, which is commonly observed in many psychiatric and neurological disorders, including MDD, schizophrenia, Alzheimer's disease, Parkinson's disease, $\mathrm{HD}, \mathrm{ADHD}$, frontotemporal dementia, traumatic brain injury, post-traumatic stress disorders and stroke (38). The use of this terminology differs across patient groups, although it is now acknowledged that the underlying symptoms overlap

${ }^{4}$ http://www.ehdn.org/ greatly (38). In neurological disorders, loss of motivation is typically categorized as the syndrome of apathy, which itself is defined as diminished motivation for physical, cognitive and/or emotional activity (44). In psychiatry-with special reference to schizophrenia-loss of motivation corresponds to negative symptom domains such as avolition (lack of motivation, sense of purpose) and anhedonia (lack/loss of pleasure) (45) (loss of motivation $=$ avolition, anhedonia). In HD many aspects can hinder the accurate diagnosis of apathy, like anergia, hopelessness and others on the negative affect and akinetic spectrum-a deeper understanding of their shared aspects is needed to better define and manage them in HD (40).

Depression can either be a disease (major depression or bipolar depression) with several ICD-10 (46) criteria needed to be met, or a symptom of decreased mood. Decreased mood can occur in various neuropsychiatric disorders, such as schizoaffective disorder, schizophrenia, bipolar disorder, MDD, stroke, Parkinson's disease, HD etc. In HD anxiety and irritability is frequently associated to the depression ${ }^{4}$.

In our study, apathy symptoms were measured by the Behavioral Assessment of the UHDRS, while depressive symptoms by the BDI. At baseline, irritability, anxiety, depression, low self-estimation, disruptive behavior and apathy dominated the clinical picture based on the Behavioral Assessment of the UHDRS. BDI detected moderate- to severe depression in 9 out of 15 patients. Both symptom domains improved significantly with CAR treatment. International guidelines for the treatment of Huntington's disease recommend the use of SSRIs or SNRIs for the treatment of either depression alone or depression combined with anxiety, suicidal ideation or impulsivity (47). However, there is a lack of evidence on specific antidepressant treatments in HD (48). A phase IIb multicentric, double-blind, placebo-controlled crossover trial with bupropion, a drug blocking the reuptake of dopamine and norepinephrine, failed to show any meaningful improvement targeting apathy in HD (16). In one case report, aripiprazole improved apathy induced by risperidone treatment (49). In our HD cohort, treatment with CAR resulted in significant improvements in both depression and apathy. This finding is crucial in the context of the large unmet need in the treatment of both apathy and depression in HD. Our study suggests that cariprazine might be a favorable therapeutic option for both symptoms.

The dopaminergic abnormalities are well-known in HD (for a comprehensive review, see Schwab et al.) (50). Altered DA signaling contributes not only to different component processes of reward, mainly mediating anticipatory phases, reinforcement processes and hedonic response $(51,52)$ but to cognitive manifestations of HD as well. The dysfunction of cognitive processing of emotion, similar to apathy, has been described in several CNS disorders such as depression (53), post-traumatic stress disorder (54) and progressive supranuclear palsy (55). In another dopamine associated disease, Parkinson's disease (PD) the cognitive deterioration was observed commonly in association with apathy $(56,57)$ : apathetic PD patients had a significant decline in memory compared with non-apathetic patients (58). In Huntington's disease, cognitive deficit is also an important non-motor hallmark of the disease. Mild 
TABLE 2 | Differences during the observation period in cognitive and behavioral dimensions.

\begin{tabular}{|c|c|c|c|c|c|c|c|c|c|c|c|c|c|c|c|}
\hline & \multicolumn{3}{|c|}{ ACE } & \multicolumn{3}{|c|}{ Symbol digit test } & \multicolumn{3}{|c|}{ Verbal fluency } & \multicolumn{3}{|c|}{ BDI } & \multicolumn{3}{|c|}{ Behavioral assessment } \\
\hline & BL & BL-W8 & BL-W12 & BL & BL-W8 & BL-W12 & BL & BL-W8 & BL-W12 & BL & BL-W8 & BL-W12 & BL & BL-W8 & BL-W12 \\
\hline P1 & 76 & 5 & 15 & 20 & 0 & 1 & 6 & 1 & 2 & 12 & 8 & -2 & 66 & 4 & -33 \\
\hline P2 & 77 & 12 & 16 & 6 & 0 & 3 & 5 & 1 & 3 & 24 & -6 & -12 & 53 & -18 & -25 \\
\hline P3 & 77 & 9 & 13 & 6 & 4 & 4 & 7 & 2 & 1 & 26 & -13 & -20 & 55 & -28 & -31 \\
\hline P5 & 86 & 8 & 10 & 18 & 5 & 9 & 10 & 2 & 4 & 30 & -24 & -24 & 73 & -32 & -49 \\
\hline P6 & 85 & -9 & -4 & 8 & 0 & 0 & 8 & -2 & -1 & 29 & 0 & -6 & 63 & 0 & -18 \\
\hline P7 & 75 & 11 & 16 & 8 & 0 & 2 & 8 & 0 & 1 & 19 & -7 & -14 & 55 & 0 & -28 \\
\hline P8 & 73 & 1 & 5 & 8 & 0 & -2 & 8 & 0 & -3 & 33 & 14 & 7 & 75 & 0 & -2 \\
\hline P9 & 67 & 14 & 16 & 3 & 0 & 2 & 2 & 1 & 3 & 20 & -4 & -8 & 41 & 0 & 0 \\
\hline P10 & 81 & 11 & 15 & 4 & 3 & 4 & 6 & 3 & 4 & 24 & -23 & -24 & 51 & -23 & -29 \\
\hline P11 & 49 & 2 & 16 & 0 & 0 & 1 & 2 & 0 & 1 & 23 & 0 & -18 & 63 & 0 & -15 \\
\hline P12 & 77 & 2 & 12 & 6 & 0 & 3 & 7 & -1 & 1 & 10 & 3 & 10 & 51 & -3 & -9 \\
\hline P13 & 87 & 3 & 3 & 20 & 5 & 10 & 6 & 1 & 1 & 11 & -4 & -11 & 41 & -7 & -19 \\
\hline P14 & 55 & 8 & 16 & 0 & 0 & 2 & 2 & 0 & 2 & 0 & 9 & 7 & 55 & 0 & -29 \\
\hline P15 & 86 & 9 & 9 & 15 & 2 & 2 & 9 & 2 & 0 & 3 & -2 & 1 & 41 & -6 & -17 \\
\hline P16 & 76 & 13 & 15 & 16 & 4 & 6 & 7 & 2 & 3 & 2 & -2 & -2 & 41 & -19 & -33 \\
\hline
\end{tabular}

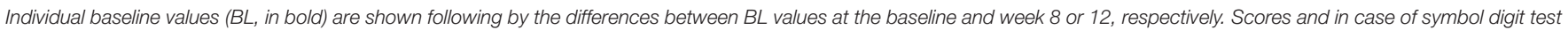
and verbal fluency correct answers within the specified time are indicated.

cognitive impairments as prefrontal symptoms are present prior to diagnosis in over half of the patients in early stages of HD (59). In many cases, similarly to psychiatric symptoms, cognitive deficits precede the onset of motor symptoms by years or even decades (41). A large multicentric study revealed that cognitive impairment is a very common feature besides depression, apathy and irritability (38). Patients with cognitive or behavioral symptoms had lower Total Functional Capacity (TFC) score of the UHDRS scale (41). In a longitudinal study of HD patients, half of those patients who were not affected by cognitive impairment at baseline experienced cognitive decline over time (60). There is a definite unmet need to improve the cognitive symptoms of HD especially in the early stage of the disease (61). In this study, treatment with cariprazine resulted in a significant improvement in the cognitive functions based on all test which was performed: the scores of the Addenbrooke Cognitive Examination, the Single Digit Modality and Verbal Fluency test significantly increased during the 12week observational period. In our cohort, the cognitive scores improved in parallel with the BDI and UHDRS Behavioral Assessment Scores. It supports the hypothesis that by influencing the dopaminergic system, especially through the D3 receptors, the motivation and the cognitive functions can be improved (6).

Our present knowledge about the neurobiology of apathy, depression, and cognitive deficits suggests that there might be some shared mechanisms between these syndromes which are present in brain disorders associated with different etiology (38). Regarding apathy, the dysfunction of circuits connecting the PFC, basal ganglia and limbic system is believed to form the neurobiological basis $(62,63)$. The contributor effect of DA as a neurotransmitter in apathy besides its known involvement in the physiology of reward and hedonic response (51) is supported by the observations that in Parkinson's disease (64), and in patients with prefrontal or basal ganglia lesions, dopaminergic medication improved apathy (65), while ceasing dopaminergic medication after deep brain stimulation for PD increased apathy $(64,66)$.

In neurodegenerative disorders, neuropathological and neuroimaging studies revealed that apathy is strongly associated with lesion or functional impairment of the anterior cingulate cortex, ventromedial and dorsolateral PFC or ventral striatum and ventral tegmental area, as well as brain regions connected to these areas (67). Studies showed that compared to controls, there was a largely convergent network of brain regions with blunted activation during appetitive and decision-making tasks, as well as consummatory or learning phases of reward processing in patients with depression who have apathy (38). It is described that the same regions involved in the higher cognitive functions and the lesions of these areas are causing cognitive dysfunction (e.g., attention disturbances). Furthermore, in depression, activation is reduced in the above-mentioned regions, although contradictory results were reported in other studies (38). Martinez-Horta et al. (68) detected by PET that deterioration in apathy (as measured by the short version of the Problem Behaviors Assessment) significantly correlated with hypometabolism in the PFC, while the changes in depressive scores were correlated with hypometabolism in parietal-temporal regions in patients with pre-symptomatic Huntington's disease. In $\mathrm{HD}$, decreases in the volume of the caudate, putamen, and the globus pallidus had the strongest correlations with clinical outcome measures for both motor and cognitive functions (69), however there is increasing evidence supporting the potential involvement of frontal lobe volume loss $(68,70)$.

Furthermore, the cognitive and mood symptoms (apathy and depression) might share common aetiological causes at 
neurotransmitter level: the dysfunction of the DA mesocortical pathway (71). In different psychiatric disorders, negative symptoms, like apathy, depression and cognitive impairment, have been associated with hypodopaminergic states in the prefrontal cortex (72). D3 partial agonist drugs, like CAR, increase dopamine levels in the PFC, normalizing the hypodopaminergic state. D3 receptors have been shown to play a distinct role in regulating excitability in layer 5 pyramidal cells in the PFC (73). Regional selective layer 5 pyramidal neuron degeneration correlates with clinical heterogeneity in HD symptom profiles (74). Also, the higher executive functions are linked to the PFC, which is partially damaged in HD. Given that the layer 5 pyramidal cells in the PFC contain D3 receptors, it can explain how HD causes impairments in motivation and how CAR is effective in restoring it.

There were some limitations to our study. Firstly, the present version of the Behavioral Assessment of the UHDRS has its limitations concerning the measurement of apathy, anhedonia and depression, since the questionnaire includes only one item intended to capture apathy and no item specifically focusing on anhedonia. Secondly, we only examined a small sample size and patient numbers were limited. Data should be confirmed by a study including a large sample size. Finally, longer follow-up time in a larger cohort is needed to validate our data.

In conclusion, our observations provide data about the positive effect of CAR on some psychiatric symptoms such as depressive mood, apathy and cognitive functions in patients with early stage of $\mathrm{HD}$. We indicated that based on the neurobiological basis of these symptoms, CAR can improve the dopamine imbalance of the prefrontal cortex and thereby the symptoms themselves. This draws attention to a symptom-based transdiagnostic approach which supports the understanding of similar symptomatology in different neuropsychiatric disorders and helps identifying new indications of pharmaceutical compounds.

\section{DATA AVAILABILITY STATEMENT}

The original contributions presented in the study are included in the article/Supplementary Material, further inquiries can be directed to the corresponding author/s.

\section{REFERENCES}

1. Aviolat H, Pinto RM, Godschall E, Murtha R, Richey HE, Sapp E, et al. Assessing average somatic CAG repeat instability at the protein level. Sci Rep. (2019) 9:19152. doi: 10.1038/s41598-019-55202-x

2. Vonsattel JP, Figlia MD. Huntington disease. J Neuropathol Exp Neurol. (1998) 57:369-84. doi: 10.1097/00005072-1998050 00-00001

3. Tabrizi SJ, Flower MD, Ross CA, Wild EJ. Huntington disease: new insights into molecular pathogenesis and therapeutic opportunities. Nat Rev Neurol. (2020) 16:529-46. doi: 10.1038/s41582-020-0389-4

4. Franco-Iborra S, Plaza-Zabala A, Montpeyo M, Sebastian D, Vila M, Martinez-Vicente M. Mutant HTT (huntingtin) impairs mitophagy in a cellular model of Huntington disease. Autophagy. (2021) 17:67289. doi: 10.1080/15548627.2020.1728096

\section{ETHICS STATEMENT}

The studies involving human participants were reviewed and approved by Regional and Institutional Research and Ethical Committee of Semmelweis University. The patients/participants provided their written informed consent to participate in this study.

\section{AUTHOR CONTRIBUTIONS}

MM and ZG: study design, patient management, neurological investigation, data interpretation, and writing the manuscript. VM: data collection, data interpretation, and writing manuscript. MF: neuropsychological testing. RC: data interpretation and writing the manuscript. KA: statistical analysis. BB: neurological investigation and writing the manuscript. All authors contributed to the article and approved the submitted version.

\section{FUNDING}

This study was supported by the Hungarian National Brain Research Program KTIA_13_NAP-A-III/6 project and the FIKP program.

\section{ACKNOWLEDGMENTS}

The authors thank the patients and their caregivers for the support of this research. Many thanks goes to Györgyi Bathori, Izabella Laszlo, and Anabella Pal for their assistance in the coordination, nursing and physiotherapeutic assistance. The institute of Genomic Medicine and Rare Disorders is the full member of the European Reference Network Rare Neurological Disorders.

\section{SUPPLEMENTARY MATERIAL}

The Supplementary Material for this article can be found online at: https://www.frontiersin.org/articles/10.3389/fpsyt. 2021.825532/full\#supplementary-material

5. Franco R, Reyes-Resina I, Navarro G. Dopamine in health and disease: much more than a neurotransmitter. Biomedicines. (2021) 9:109. doi: 10.3390/biomedicines9020109

6. Kiss B, Laszlovszky I, Krámos B, Visegrády A, Bobok A, Lévay G, et al. Neuronal dopamine D3 receptors: translational implications for preclinical research and CNS disorders. Biomolecules. (2021) 11:104. doi: 10.3390/biom11010104

7. van Oostrom JCH, Dekker M, Willemsen ATM, de Jong BM, Roos RAC, Leenders KL. Changes in striatal dopamine D2 receptor binding in pre-clinical Huntington's disease. Eur J Neurol. (2009) 16:226-31. doi: 10.1111/j.1468-1331.2008.02390.x

8. Antonini A, Leenders KL, Spiegel R, Meier D, Vontobel P, Weigell-Weber $\mathrm{M}$, et al. Striatal glucose metabolism and dopamine D2 receptor binding in asymptomatic gene carriers and patients with Huntington's disease. Brain. (1996) 119:2085-95. doi: 10.1093/brain/119.6.2085 
9. Garrett MC, Soares-da-Silva P. Increased cerebrospinal fluid dopamine and 3,4-dihydroxyphenylacetic acid levels in huntington's disease: evidence for an overactive dopaminergic brain transmission. J Neurochem. (1992) 58:1016. doi: 10.1111/j.1471-4159.1992.tb09283.x

10. Hedreen JC, Folstein SE. Early loss of neostriatal striosome neurons in huntington's disease. J Neuropathol Exp Neurol. (1995) 54:10520. doi: 10.1097/00005072-199501000-00013

11. Pierce RC, Rebec GV. Iontophoresis in the neostriatum of awake, unrestraine rats: differential effects of dopamine, glutamate and ascorbate on motor- and nonmotor-related neurons. Neuroscience. (1995) 67:31324. doi: 10.1016/0306-4522(95)00012-8

12. Dash D, Mestre TA. Therapeutic update on huntington's disease: symptomatic treatments and emerging disease-modifying therapies. Neurotherapeutics. (2020) 17:1645-59. doi: 10.1007/s13311-020-00891-w

13. Frank S. Tetrabenazine as anti-chorea therapy in Huntington disease: an open-label continuation study. Huntington study Group/TETRA-HD investigators. BMC Neurol. (2009) 9:62. doi: 10.1186/1471-2377-9-62

14. Rodrigues FB, Duarte GS, Costa J, Ferreira JJ, Wild EJ. Tetrabenazine Vs. deutetrabenazine for huntington's disease: twins or distant cousins? Mov Dis Clin Practice. (2017) 4:582-5. doi: 10.1186/s40734-017-0067-x

15. Claassen DO, Carroll B, de Boer LM, Wu E, Ayyagari R, Gandhi $\mathrm{S}$, et al. Indirect tolerability comparison of deutetrabenazine and tetrabenazine for huntington disease. J Clin Mov Dis. (2017) 4:3. doi: 10.1186/s40734-017-0051-5

16. Gelderblom H, Wüstenberg T, McLean T, Mütze L, Fischer W, Saft C, et al. Bupropion for the treatment of apathy in Huntington's disease: a multicenter, randomised, double-blind, placebo-controlled, prospective crossover trial. PLoS ONE. (2017) 12:e0173872. doi: 10.1371/journal.pone.0173872

17. Li Y, Hai S, Zhou Y, Dong BR. Cholinesterase inhibitors for rarer dementias associated with neurological conditions. Cochrane Database Syst Rev. (2015) CD009444. doi: 10.1002/14651858.CD009444.pub3

18. Calabrese F, Tarazi FI, Racagni G, Riva MA. The role of dopamine $\mathrm{D}_{3}$ receptors in the mechanism of action of cariprazine. CNS Spect. (2020) 25:343-51. doi: 10.1017/S109285291900083X

19. Kiss B, Horváth A, Némethy Z, Schmidt É, Laszlovszky I, Bugovics G, et al. Cariprazine (RGH-188), a dopamine $\mathrm{D}(3)$ receptor-preferring, $\mathrm{D}(3) / \mathrm{D}(2)$ dopamine receptor antagonist-partial agonist antipsychotic candidate: in vitro and neurochemical profile. J Pharmacol Exp Ther. (2010) 333:32840. doi: 10.1124/jpet.109.160432

20. Stahl SM. Mechanism of action of cariprazine. CNS Spectrums. (2016) 21:1237. doi: 10.1017/S1092852916000043

21. Stahl SM, Laredo S, Morrissette DA. Cariprazine as a treatment across the bipolar I spectrum from depression to mania: mechanism of action and review of clinical data. Thera Adv Psychopharmacol. (2020) 10: 2045125320905752. doi: 10.1177/2045125320905752

22. Beck AT. An inventory for measuring depression. Arch General Psychiatry. (1961) 4:561. doi: 10.1001/archpsyc.1961.01710120031004

23. Huntington Study Group. Unified Huntington's disease rating scale: reliability and consistency. Mov Dis. (1996) 11:136-42. doi: 10.1002/mds.870110204

24. Hodges JR, Larner AJ. Addenbrooke's cognitive examinations: ACE, ACER, ACE-III, ACEapp, M-ACE. In: Larner AJ, editors. Cognitive Screening Instruments. Cham: Springer International Publishing (2017). p. 109-37.

25. Larner AJ ed. Cognitive Screening Instruments: A Practical Approach. London: Springer International Publishing (2016).

26. Fava M, Durgam S, Earley W, Lu K, Hayes R, Laszlovszky I, et al. Efficacy of adjunctive low-dose cariprazine in major depressive disorder. Int Clin Psychopharmacol. (2018) 33:312-21. doi: 10.1097/YIC.0000000000000235

27. Durgam S, Earley W, Guo H, Li D, Németh G, Laszlovszky I, et al. Efficacy and safety of adjunctive cariprazine in inadequate responders to antidepressants. $J$ Clin Psychiatry. (2016) 77:371-8. doi: 10.4088/JCP.15m10070

28. Németh G, Laszlovszky I, Czobor P, Szalai E, Szatmári B, Harsányi $\mathrm{J}$, et al. Cariprazine versus risperidone monotherapy for treatment of predominant negative symptoms in patients with schizophrenia: a randomised, double-blind, controlled trial. Lancet. (2017) 389:1103-13. doi: 10.1016/S0140-6736(17)30060-0

29. Marder S, Fleischhacker WW, Earley W, Lu K, Zhong Y, Németh $G$, et al. Efficacy of cariprazine across symptom domains in patients with acute exacerbation of schizophrenia: pooled analyses from 3 phase II/III studies. Eur Neuropsychopharmacol.

(2019) 29:127-36. doi: 10.1016/j.euroneuro.2018.10.008

30. Fleischhacker W, Galderisi S, Laszlovszky I, Szatmári B, Barabássy Á, Acsai $\mathrm{K}$, et al. The efficacy of cariprazine in negative symptoms of schizophrenia: Post hoc analyses of PANSS individual items and PANSS-derived factors. Eur Psychiatry. (2019) 58:1-9. doi: 10.1016/j.eurpsy.2019.01.015

31. Vieta E, Calabrese JR, Whelan J, Tohen M, Earley WR. The efficacy of cariprazine on function in patients with bipolar depression: a post hoc analysis of a randomized controlled trial. Curr Med Res Opinion. (2021) 37:163543. doi: 10.1080/03007995.2021.1932446

32. Mcintyre RS, Vieta E, Earley W, Patel M. Effects of cariprazine on cognition in patients with bipolar mania or mixed states: post hoc analysis from 3 randomized, controlled phase iii studies. CNS Spect. (2021) 26:182. doi: 10.1017/S1092852921000213

33. Jimoh IJ, Sebe B, Balicza P, Fedor M, Pataky I, Rudas G, et al. WernickeKorsakoff syndrome associated with mtDNA disease. Therap Adv Neurol Dis. (2020) 13:1756286420938972. doi: 10.1177/1756286420938972

34. Sanders LO, Miller JJ. Cariprazine may decrease substance abuse in patients with bipolar i disorder. Psychiatric Times. (2019) 36:10-3.

35. Truong TT, Li B. Case series: cariprazine for treatment of methamphetamine use disorder. Am J Addict. (2021) 1-4. doi: 10.1111/ajad.13241

36. de Berardis D, Vellante F, Fornaro M, Orsolini L, Valchera A, Baroni G, et al. Rapid improvement of obsessive-compulsive disorder associated with schizophrenia with cariprazine add-on in a subject under paliperidone long-acting injection. Int Clin Psychopharmacol. (2020) 35:113-8. doi: 10.1097/YIC.0000000000000284

37. Grant JE, Chamberlain SR. Cariprazine treatment of borderline personality disorder: a case report. Psychiatry Clin Neurosci. (2020) 74:511-2. doi: 10.1111/pcn.13094

38. Husain M, Roiser JP. Neuroscience of apathy and anhedonia: a transdiagnostic approach. Nat Rev Neurosci. (2018) 19:470-84. doi: 10.1038/s41583-018-0029-9

39. Thompson JC, Harris J, Sollom AC, Stopford CL, Howard E, Snowden JS, et al. Longitudinal evaluation of neuropsychiatric symptoms in huntington's disease. J Neuro Clin Neurosci. (2012) 24:53-60. doi: 10.1176/appi.neuropsych.11030057

40. Camacho M, Barker RA, Mason SL. Apathy in huntington's disease: a review of the current conceptualization. J Alzheimer's Dis Parkinsonism. (2018) 08:19. doi: 10.4172/2161-0460.1000431

41. McAllister B, Gusella JF, Landwehrmeyer GB, Lee J-M, MacDonald ME, Orth $\mathrm{M}$, et al. Timing and impact of psychiatric, cognitive, and motor abnormalities in huntington disease. Neurology. (2021) 96:e2395-406. doi: 10.1212/WNL.0000000000011893

42. Levy ML, Cummings JL, Fairbanks LA, Masterman D, Miller BL, Craig AH, et al. Apathy is not depression. J Neuro Clin Neurosci. (1998) 10:3149. doi: 10.1176/jnp.10.3.314

43. Ishizaki J, Mimura M. Dysthymia and apathy: diagnosis and treatment. Dep Res Treat. (2011) 2011:1-7. doi: 10.1155/2011/893905

44. Marin RS. Apathy: a neuropsychiatric syndrome. J Neuro Clin Neurosci. (1991) 3:243-54. doi: 10.1176/jnp.3.3.243

45. Marder SR, Galderisi S. The current conceptualization of negative symptoms in schizophrenia. World Psychiatry. (2017) 16:14-24. doi: 10.1002/wps.20385

46. World Health Organization (WHO). The ICD-10 Classification of Mental and Behavioural Disorders. Genève: World Health Organization (1993).

47. Bachoud-Lévi A-C, Ferreira J, Massart R, Youssov K, Rosser A, Busse M, et al. International guidelines for the treatment of huntington's disease. Front Neurol. (2019) 10:1-8. doi: 10.3389/fneur.2019.00710

48. Gubert C, Renoir T, Hannan AJ. Why woody got the blues: the neurobiology of depression in Huntington's disease. Neurobiol Dis. (2020) 142:104958. doi: 10.1016/j.nbd.2020.104958

49. Ciammola A, Sassone J, Colciago C, Mencacci NE, Poletti B, Ciarmiello A, et al. Aripiprazole in the treatment of Huntington's disease: a case series. Neuro Dis Treat. (2009) 5:1-4. doi: 10.2147/NDT.S4165

50. Schwab LC, Garas SN, Garas SN, Drouin-Ouellet J, Mason SL, Stott SR, et al. Dopamine and Huntington's disease. Exp Rev Neurother. (2015) 15:44558. doi: 10.1586/14737175.2015.1025383

51. Berridge KC, Robinson TE. What is the role of dopamine in reward: hedonic impact, reward learning, or incentive salience? 
Brain Res Rev. (1998) 28:309-69. doi: 10.1016/S0165-0173(98) 00019-8

52. Wise RA. Dopamine, learning and motivation. Nat Rev Neurosci. (2004) 5:483-94. doi: 10.1038/nrn1406

53. Villalobos D, Pacios J, Vázquez C. Cognitive control, cognitive biases and emotion regulation in depression: a new proposal for an integrative interplay model. Front Psychol. (2021) 12:1-18. doi: 10.3389/fpsyg.2021.628416

54. Brown VM, Morey RA. Neural systems for cognitive and emotional processing in posttraumatic stress disorder. Front Psychol. (2012) 3:114. doi: 10.3389/fpsyg.2012.00449

55. Ghosh BCP, Rowe JB, Calder AJ, Hodges JR, Bak TH. Emotion recognition in progressive supranuclear palsy. J Neurol Neuro Psychiatry. (2009) 80:11435. doi: 10.1136/jnnp.2008.155846

56. Kudlicka A, Clare L, Hindle JV. Executive functions in Parkinson's disease: systematic review and meta-analysis. Mov Dis. (2011) 26:230515. doi: $10.1002 / \mathrm{mds} .23868$

57. Veselý B, Rektor I. The contribution of white matter lesions (WML) to Parkinson's disease cognitive impairment symptoms: a critical review of the literature. Parkinsonism Rel Dis. (2016) 22:S166-70. doi: 10.1016/j.parkreldis.2015.09.019

58. Alzahrani H, Venneri A. Cognitive and neuroanatomical correlates of neuropsychiatric symptoms in Parkinson's disease: a systematic review. J Neurol Sci. (2015) 356:32-44. doi: 10.1016/j.jns.2015.06.037

59. Duff K, Paulsen JS, Beglinger LJ, Langbehn DR, Wang C, Stout JC, et al. "Frontal" behaviors before the diagnosis of huntington's disease and their relationship to markers of disease progression: evidence of early lack of awareness. J Neuro Clin Neurosci. (2010) 22:196-207. doi: 10.1176/jnp.2010.22.2.196

60. Zhang Y, Zhou J, Gehl CR, Long JD, Johnson H, Magnotta VA, et al. Mild cognitive impairment as an early landmark in huntington's disease. Front Neurol. (2021) 12:1-10. doi: 10.3389/fneur.2021.678652

61. Paulsen JS. Cognitive impairment in huntington disease: diagnosis and treatment. Curr Neurol Neurosci Rep. (2011) 11:474-83. doi: 10.1007/s11910-011-0215-x

62. Levy R, Dubois B. Apathy and the functional anatomy of the prefrontal cortex-basal ganglia circuits. Cerebral Cortex. (2006) 16:916-28. doi: 10.1093/cercor/bhj043

63. Németh G. Some theoretical and practical aspects of the disturbances of consciousness with special reference to akinetic mutism. Funct Neurol. (1988) 3:9-28.

64. Czernecki V. Motivation, reward, and Parkinson's disease: influence of dopatherapy. Neuropsychologia. (2002) 40:2257-67. doi: 10.1016/S0028-3932(02)00108-2

65. Blundo C, Gerace C. Dopamine agonists can improve pure apathy associated with lesions of the prefrontal-basal ganglia functional system. Neurol Sci. (2015) 36:1197-201. doi: 10.1007/s10072-014-2061-5

66. Czernecki V, Schüpbach M, Yaici S, Lévy R, Bardinet E, Yelnik J, et al. Apathy following subthalamic stimulation in Parkinson disease: a dopamine responsive symptom. Mov Dis. (2008) 23:964-9. doi: 10.1002/mds.21949
67. Németh G, Hegedus K, Molnár L. Akinetic mutism associated with bicingular lesions: clinicopathological and functional anatomical correlates. Eur Arch Psychiatry Neuro Sci. (1988) 237:218-22. doi: 10.1007/BF00449910

68. Martinez-Horta S, Perez-Perez J, Sampedro-Santalo F, Pagonabarraga J, Carceller M, de Bobadilla R, et al. E30 brain metabolic correlates of apathy and depression in pre-manifested huntington's disease: a 18-fgd pet study. J Neurol Neuro Psychiatry. (2014) 85:A47. doi: 10.1136/jnnp-2014-309 032.133

69. Kinnunen KM, Schwarz AJ, Turner EC, Pustina D, Gantman EC, Gordon MF, et al. Volumetric MRI-based biomarkers in huntington's disease: an evidentiary review. Front Neurol. (2021) 12:1-12. doi: 10.3389/fneur.2021.712555

70. Aylward EH, Anderson NB, Bylsma FW, Wagster M v., Barta PE, Sherr M, et al. Frontal lobe volume in patients with Huntington's disease. Neurology. (1998) 50:252-8. doi: 10.1212/WNL.50.1.252

71. Sierra M, Carnicella S, Strafella AP, Bichon A, Lhommée E, Castrioto A, et al. Apathy and impulse control disorders: yin \&amp; yang of dopamine dependent behaviors. J Parkinson's Dis. (2015) 5:62536. doi: 10.3233/JPD-150535

72. Sekiguchi H, Pavey G, Dean B. Altered levels of dopamine transporter in the frontal pole and dorsal striatum in schizophrenia. Npj Schizophrenia. (2019) 5:20. doi: 10.1038/s41537-019-0087-7

73. Clarkson RL, Liptak AT, Gee SM, Sohal VS, Bender KJ. D3 receptors regulate excitability in a unique class of prefrontal pyramidal cells. J Neurosci. (2017) 37:5846-60. doi: 10.1523/JNEUROSCI.0310-17.2017

74. McColgan P, Joubert J, Tabrizi SJ, Rees G. The human motor cortex microcircuit: insights for neurodegenerative disease. Nat Rev Neurosci. (2020) 21:401-15. doi: 10.1038/s41583-020-0315-1

\section{Conflict of Interest: RC and KA are employees of Gedeon Richter Plc.}

The remaining authors declare that the research was conducted in the absence of any commercial or financial relationships that could be construed as a potential conflict of interest.

Publisher's Note: All claims expressed in this article are solely those of the authors and do not necessarily represent those of their affiliated organizations, or those of the publisher, the editors and the reviewers. Any product that may be evaluated in this article, or claim that may be made by its manufacturer, is not guaranteed or endorsed by the publisher.

Copyright (C) 2022 Molnar, Molnar, Fedor, Csehi, Acsai, Borsos and Grosz. This is an open-access article distributed under the terms of the Creative Commons Attribution License (CC BY). The use, distribution or reproduction in other forums is permitted, provided the original author(s) and the copyright owner(s) are credited and that the original publication in this journal is cited, in accordance with accepted academic practice. No use, distribution or reproduction is permitted which does not comply with these terms. 